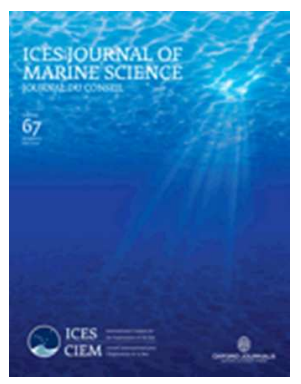

\title{
Shifts in Spawning Phenology of Cod Linked to Rising Sea Temperatures
}

\begin{tabular}{|r|l|}
\hline Journal: & ICES Journal of Marine Science \\
\hline Manuscript ID & ICESJMS-2016-469.R2 \\
\hline Manuscript Types: & Original Article \\
\hline Date Submitted by the Author: & 07-Feb-2017 \\
\hline Complete List of Authors: & $\begin{array}{l}\text { McQueen, Kate; University of Aberdeen, } \\
\text { Marshall, Catherine; University of Aberdeen, School of Biological Sciences }\end{array}$ \\
\hline Keyword: & $\begin{array}{l}\text { cod, Gadus morhua, phenology, spawning, climate change, North Sea, } \\
\text { Irish Sea }\end{array}$ \\
\hline \multicolumn{2}{|l}{} \\
\hline
\end{tabular}

SCHOLARONE ${ }^{m}$

Manuscripts 
1 Shifts in Spawning Phenology of Cod Linked to Rising Sea Temperatures

9

2 Kate McQueen ${ }^{1 *}$ and C. Tara Marshall ${ }^{1}$

$3{ }^{1}$ Zoology Building, University of Aberdeen, Tillydrone Avenue, Aberdeen,

$4 \quad$ AB24 2TZ, Scotland, U.K.

5 *Corresponding Author: email: k.mcqueen.15@aberdeen.ac.uk

6 Abstract

7 Warming temperatures caused by climate change have the potential to impact spawning

8 phenology of temperate marine fish as some species have temperature-dependent gonadal

9 development. Inter-annual variation in the timing of Atlantic cod (Gadus morhua)

10 spawning in the northern North Sea, central North Sea and Irish Sea was estimated by

11 calculating an annual peak roe month (PRM) from records of roe landings spanning the

12 last three decades. A trend towards earlier PRM was found in all three regions, with

13 estimates of shifts in PRM ranging from 0.9 to 2.4 weeks per decade. Temperatures

14 experienced by cod during early vitellogenesis correlated negatively with PRM,

15 suggesting that rising sea temperatures have contributed to a shift in spawning phenology.

16 A concurrent reduction in the mean size of spawning females excluded the possibility that

17 earlier spawning was due to a shift in size structure towards larger individuals, as large

18 cod spawn earlier than smaller-sized individuals in the North Sea. Further research into

19 the effects of climate change on the phenology of different trophic levels within the North

20 Sea ecosystem should be undertaken to determine whether climate change-induced shifts

21 in spawning phenology will result in a temporal mismatch between cod larvae and their

22 planktonic prey. 
1 Keywords: cod, Gadus morhua, phenology, spawning, climate change, North Sea, Irish

2 Sea

3 Introduction

4 Sea temperatures are warming at unprecedented rates as a result of global climate change

5 (IPCC, 2013). These changing environmental conditions have the potential to impact

6 marine animal and plant populations, including fish, through changes in distribution,

7 phenology and physiology (Hughes, 2000). Although climate change-induced shifts in

8 phenology are now well documented for terrestrial plant and animal species (e.g. Roy and

9 Sparks, 2000, Roberts et al., 2015), research focusing on the impact of climate change on

10 phenology of marine fish is more limited. Phenology can impact the fitness of marine fish

11 by influencing whether life-history events such as spawning occur under optimal

12 conditions. For example, the match/mismatch hypothesis (Cushing, 1975) relates survival

13 rates of fish larvae to the match in timing between a "critical period" of larval first-

14 feeding (Hjort, 1914) and the peak of spring plankton blooms in temperate marine

15 environments (Cushing, 1990). Cod larvae depend on copepod prey for survival and

16 changes in the plankton community during the main period of larval cod presence has

17 been linked to variation in recruitment, highlighting this as an important mechanism of

18 bottom-up control (Beaugrand et al., 2003). Changes in spawning phenology therefore

19 have the potential to impact fish recruitment, if the phenology of prey and predator

20 become decoupled (e.g. Platt et al., 2003).

21 The physiological mechanism through which temperature influences spawning time of

22 Atlantic cod (Gadus morhua, hereafter referred to as cod) has been well described

23 through experimental studies. Vitellogenesis is initiated at the autumnal equinox but the

24 subsequent rate of oocyte development is influenced by temperature (Kjesbu et al., 2010). 
1 Warmer temperatures result in a faster rate of oocyte development and therefore an earlier

2 spawning time (Kjesbu et al., 2010). Changes in temperature during early vitellogenesis

3 have a greater effect on spawning time than changes in temperature during late

4 vitellogenesis (Kjesbu, 1994). In addition to the effects of temperature, a physiological

5 link between body size and spawning time can also contribute to the determination of cod

6 spawning phenology (Kjesbu et al., 2010). Larger cod generally spawn earlier than

7 smaller individuals in warmer environments such as the North and Irish Seas, possibly

8 due to their higher thermal sensitivity (Kjesbu et al., 2010).

9 Despite the potential for the reproductive phenology of commercially exploited temperate

10 marine fish stocks to be influenced by climate change, with potential implications for

11 fitness and recruitment, the majority of research on the response of fish populations to

12 rising temperatures has so far focused on changes in spatial distribution and productivity

13 (e.g. Clark et al., 2003, Perry et al., 2005, Brander, 2007, Dulvy et al., 2008, Engelhard et

14 al., 2011). One exception is the recent study by Fincham et al. (2013) which examined 40

15 years of maturity-stage data for sole (Solea solea), collected through an intensive

16 monitoring scheme of fisheries landings from waters around the UK. A shift in spawning

17 phenology of ca. 1.5 weeks per decade across four populations of sole was detected, and

18 this shift correlated with rising winter sea surface temperature (SST) (Fincham et al.,

19 2013). Previous research on the impacts of temperature on spawning time of cod has also

20 revealed a relationship between spawning time and temperature in wild cod off the coast

21 of Newfoundland (Hutchings and Myers, 1994) and in the Baltic Sea (Wieland et al.,

22 2000). Subsequent research investigating the link between spawning time and sea

23 temperature for cod in the North Sea did not find evidence to support this hypothesis, but

24 these results may have been constrained by small sample sizes and a restricted time series

25 (Morgan et al., 2013). 
1 Investigations into phenological shifts in marine fish populations are uncommon due

2 partly to the limited availability of long-term datasets with a high degree of intra-annual

3 temporal resolution. The resolution of scientific sampling programmes is limited both

4 temporally and spatially (e.g. Carscadden et al., 1996, Greve et al., 2005) although

5 exceptions do exist (e.g. Hutchings and Myers, 1994, Fincham et al., 2013). There is

6 potential for systematic, industry-based data sources to provide long-term datasets for

7 commercial species. For example, catch records from the fishing industry have been used

8 to successfully explore variation in the timing of annual migrations of tuna (Thunnus

9 thynnus) (Dufour et al., 2010) and mackerel (Scomber scombrus) (Jansen and Gisalson,

10 2011). The collection of industry data relevant to determining spawning time is hindered

11 by the fact that, unlike sole, in Scotland and Ireland gadoids such as cod are gutted at sea,

12 precluding the direct assessment of maturity status when landed. However, for species for

13 which there is a roe market there is potential for fisheries statistics on timing and quantity

14 of roe landings to provide long-term data relating to spawning time. As cod roe is of

15 highest commercial value when cod ovaries are ripe or vitellogenic (Katsiadaki et al.,

16 1999) peaks in roe landings can be used to infer timing of spawning. Pederson (1984)

17 demonstrated how the relationship between cod and cod roe landings could be used to

18 estimate the timing of spawning of Barents Sea cod. However, the use of fisheries data

19 can introduce bias into analysis which must be accounted for when interpreting results. In

20 particular, variation in fishing effort (e.g. Dufour et al., 2010) and fluctuations in demand

21 for products such as roe (e.g. Pederson, 1984) can potentially influence the results. A

22 detailed understanding of the fishery is therefore required when using fisheries-dependent

23 data to investigate the ecology of an exploited species.

24 In the North Sea, sea temperatures have been warming at a rate of $0.2-0.6^{\circ} \mathrm{C}$ per decade

25 over the past thirty years (Baudron et al., 2014). North Sea temperatures have been 
1

increasing at rates faster than global averages, with summer temperatures increasing at particularly rapid rates (Belkin, 2009). The North Sea is therefore well-suited to investigating how warming temperatures are affecting reproduction dynamics of wild fish stocks. Although synchronous changes in individual growth rate across a varied range of fish species in response to climate change have already been demonstrated in the North Sea, North Sea cod was a notable exception (Baudron et al., 2014). North Sea cod from different regions can tolerate a wide range of temperatures (Righton et al., 2010) and generally display site fidelity to historic spawning sites (e.g. Neat et al. 2014). They will not necessarily migrate to cooler waters that are available even when experiencing temperatures that are apparently super-optimal (Neat and Righton, 2007). This evidence suggests that adult cod in the North Sea may not yet have made large-scale distributional shifts to cooler waters. Given that there is little evidence for putative impacts of warming temperatures on growth and distribution of North Sea cod the possibility of a climate change-induced shift in cod spawning phenology deserves investigation.

The objectives of this study were firstly to investigate whether spawning phenology of cod in the North Sea has shifted over time, and secondly whether shifts in spawning phenology are related to warming trends in sea temperature. Based on the experimental work by Kjesbu et al. (2010), cod spawning phenology was hypothesised to have shifted to earlier in the year in response to warming temperatures caused by climate change due to the physiological link between rate of oocyte maturation and water temperature. To test this, $_{2}$ roe landings from the North Sea to Scotland recorded over a 30 year period were used to calculate peak roe month (PRM) which was used as a proxy for the commencement of spawning. PRM was calculated from peaks in roe landings and from peaks in a roe index, an aggregate measure of roe production that is conceptually analogous to a gonadal somatic index estimated at the individual-level. Comparable data 
1

21 Government. Roe landings data were available as the total monthly landings to each port.

22 This restricted the temporal resolution of subsequent analysis to month. The International

23 Council for Exploration of the Sea (ICES) fishing area where the roe originated was the 24 only available information relating to the location of catches. The roe landed to Scotland 
1 from the North Sea originated from either ICES fishing area IVa, in the northern North

2 Sea, or from ICES fishing area IVb, the central North Sea (hereafter referred to as IVa

3 and IVb) (Figure 1). Roe data from IVa and IVb were analysed separately, in an attempt

4 to distinguish between the separate populations of cod which spawn in the northern and

5 central North Sea (Neat et al., 2014). Data on live weight of cod landed monthly to

6 Scottish ports from IVa and IVb were obtained from the same source and used to

7 calculate the roe index described below.

8 Records of daily landed weight of roe per vessel from ICES fishing area VIIa (the Irish

9 Sea, hereafter referred to as VIIa) (Figure 1) were obtained from the Centre of

10 Environment, Fisheries and Aquaculture Science (Cefas). Records were available for the

11 years 1982 to 2014. Although there is evidence suggesting that the cod spawning in the

12 eastern and western Irish Sea comprise two separate populations (Armstrong, 2001), it

13 was not possible to distinguish between separate cod stocks due to the spatial resolution

14 of the data. Although landings data were available per day for VIIa, the index of

15 spawning phenology was calculated to resolution of month for consistency with the North

16 Sea data.

17 The annual weight of roe landed from all regions has decreased over time (Figure 2). This

18 decrease in roe landings may be attributable to a combination of declining market for roe,

19 a reduction in cod quotas over the study period (ICES, 2015a), and particularly in the case

20 of the Irish Sea due to the decline in cod abundance (ICES, 2014). A sharp reduction in

21 landed weight of roe from VIIa is noticeable in 2000, when the Irish Sea cod fishery was

22 closed (ICES, 2005) (Figure 2). In the North Sea, monthly landed weight of roe from IVa

23 was consistently higher than from IVb (Figure 2). 
1 Information on the species of roe landed was not recorded in the landings dataset, so an

2 assumption was made that all of the roe landed was cod. To reduce the potential

3 contamination from other species, only roe data from the months during which cod are

4 likely to be maturing and spawning were used. Consequently, only roe landings from

5 December to April were extracted from the North Sea dataset, and landings from January

6 to May were extracted from the Irish Sea dataset, to encompass the spawning seasons of

7 North Sea cod and Irish Sea cod respectively (Brander, 1994). The data extraction

8 excluded herring (Clupea harengus) roe, which spawn between August and October

9 (Rogers and Stocks, 2001). Roe from haddock (Melanogrammus aeglefinus), ling (Molva

10 molva), saithe (Pollachius virens), whiting (Merlangius merlangus) and hake (Merluccius

11 merluccius) could potentially be mixed in with cod roe given that the spawning time of

12 these species overlaps with cod (Rogers and Stocks, 2001). Of these species, only

13 haddock roe could be landed in large enough quantities to contaminate the dataset

14 significantly.

15 Questionnaires

16 To examine the validity of the assumption that cod dominate the landed roe in the months

17 used for the analysis (see above), a questionnaire-based survey of North Sea demersal

18 fishermen who land to Scottish ports was conducted. The survey was undertaken at a

19 skipper's exposition in Aberdeen (27 $7^{\text {th }}$ and $28^{\text {th }}$ May 2016), an event attended by ca. 89

20 demersal fishermen, many of whom are based in Scotland and fish regularly in the North

21 Sea. Although a fully randomised design could not be implemented, this event

22 nevertheless provided a convenient opportunity to question many active and retired

23 fishermen from across the country. Of the attendees approached, 32 fishermen who had

24 landed roe from the North Sea to Scottish ports between the years 1985 and 2014 agreed

25 to complete a questionnaire. The questionnaire consisted of a mix of closed- and open- 
1 ended questions_(Supplementary Material S1). Participants were asked a series of simple

3 asked which species of roe they landed, and what proportion of roes landed were cod.

4 Answers gathered from the survey were used to qualitatively inform interpretation of

5 results that are based on assumptions regarding the species composition of the roe

6 landings data.

$7 \quad$ Temperature data

8 As a demersal species, sea bottom temperature would be most appropriate for

9 investigating the impacts of temperature on cod phenology. However, a complete sea

10 bottom temperature data set which covered the full spatial and temporal scale of this

11 study was not available. The North Sea, which can be described as stratified throughout

12 autumn in some areas, becomes well-mixed in winter (Connor et al., 2006). During

13 autumn, the stratification of the Irish Sea breaks down completely, resulting in a well-

14 mixed water column (Connor et al., 2006). SST therefore provides an approximation of

15 temperatures at deeper depths in these regions during autumn and winter, assuming that

16 the temporal trend in SST is the same as the temporal trend in sea bottom temperature.

17 SST has been widely used as an indicator of ocean climate in studies relating aspects of

18 cod ecology to temperature (e.g. Planque and Frédou, 1999, Armstrong et al., 2004,

19 Engelhard et al., 2014). Therefore, SST was considered appropriate here as a relevant

20 proxy for the ambient temperature experienced by cod.

21 Median monthly SSTs were extracted from the Hadley Centre Sea Ice and Sea Surface

22 Temperature data set (HadISST1)

23 (http://www.metoffice.gov.uk/hadobs/hadisst/data/download.html). The HadISST1

24 dataset is maintained by the UK Met Office and is based on opportunistic sampling from 
1 merchant ships and research vessels, but with extensive processing applied to minimize

2 the potential impact of sampling biases (Rayner et al., 2003). This dataset provides

3 complete global coverage of monthly SST estimates on a $1^{\circ}$ latitude-longitude grid,

4 dating back to 1871 (Rayner et al., 2003). For each year of this study, mean autumn

5 (September, October, November) and mean winter (December, January, February) SST

6 estimates were calculated for each fishing area, to match the spatial resolution of the roe

7 landings data (see Figure 1). Temperatures during these seasons were assumed to

8 represent the ambient thermal environment experienced by cod during early (autumn) and

9 late (winter) vitellogenesis.

10 Length data

11 Data on the length and maturity stage of North Sea cod were obtained from the North Sea

12 international bottom trawl survey (NS-IBTS) co-ordinated by ICES. These data were

13 downloaded from the DATRAS database (https://datras.ices.dk) as a Sex Maturity Age

14 Length Key (SMALK) dataset. Data from Quarter 1 surveys (conducted during January-

15 February) were used to estimate the length of spawners. Data for female fish classed as

16 maturing, mature, spawning or spent, and which were sampled from ICES sampling area

171 (ICES, 2015b) were extracted from the DATRAS dataset. This restrictive definition of

18 spawners excluded male and immature fish, and fish which were caught outside of fishing

19 area IVa. Lengths of spawners in fishing area IVb were obtained using the same dataset.

20 As IVb crosses the boundaries of several sampling areas, and encompasses no single area

21 in its entirety, the lengths of spawners from sampling areas 2, 3, 4, 6 and 7 (ICES, 2015b)

22 were used to infer average length of spawners in IVb. There were no comparable length

23 data available for Irish Sea cod which covered the extent of the study period. 
1 Indices of spawning phenology

2 Peak roe month

3 The annual peak in roe landings, referred to here as the Peak Roe Month (PRM), was

4 used as an index of spawning phenology. The PRM is assumed to indicate the

5 commencement of the spawning period as cod roe is of the highest commercial value just

6 prior to spawning. The quality of roes decreases and the proportion of roes discarded

7 increases once spawning commences (Pederson, 1984, Katsiadaki et al., 1999). For each

8 year in the time series (y) the PRM was calculated as a weighted mean using the

9 following equation:

10

$$
P R M_{y}=\frac{\sum w_{y, i} m_{y, i}}{\sum w_{y, i}}
$$

11 where $\mathrm{w}_{\mathrm{y}, \mathrm{i}}$ is the weighting factor associated with total landings recorded monthly at

12 each port (i), each year(y) and $\mathrm{m}_{\mathrm{y}, \mathrm{i}}$ is the month number when these landings occurred.

13 Month numbers were assigned sequentially from 1 for December to 6 for May. These

14 month numbers were used for analysis only and were converted to the commonly used

15 notation for presentation of results, i.e. 12 for December to 5 for May. Two alternative

16 weighting factors (w) were used to calculate PRM. For IVa and IVb, PRM was estimated

17 using total landed weight of roe $\left(\mathrm{LW}_{\mathrm{R}}\right)$ per port per month as the weighting factor. For

18 VIIa, the resolution of the available data was slightly different than for the North Sea

19 data. In the Irish Sea, daily landings were recorded per vessel. Therefore, when

20 calculating PRM for VIIa, the notation of the equation is as follows:

21

$$
P R M_{y}=\frac{\sum w_{y, l} m_{y, l}}{\sum w_{y, l}}
$$


1 where 1 denotes the landing from a vessel. Therefore in Equation 1.2, $\mathrm{w}_{\mathrm{y}, \mathrm{l}}$ is the weighting

2 factor associated with a landing from a single ship, and $\mathrm{m}_{\mathrm{y}, 1}$ is the month that this landing

3 occurred. In this way, PRM was calculated using the highest resolution data available for

4 each dataset.

5 The calculation of PRM assumes that annual peaks in $\mathrm{LW}_{\mathrm{R}}$ are related consistently to

6 spawning phenology over time. Total monthly roe landings were explored graphically to

7 confirm that they formed a roughly bell-shaped distribution each year. It is possible that

8 temporal variation in fishing effort may influence the timing of peaks in roe landings. To

9 address this potential source of bias, a roe index was calculated (described below) and

10 used as an alternative weighting factor in estimation of PRM.

11 Roe index

12 Analogous to a Gonadal Somatic Index (GSI, estimated as the proportion of total weight

13 of an individual that is comprised by the gonad), the Roe Index (RI) was calculated for

14 the monthly landings to each port, each year using the following formula:

$$
R I_{i}=\frac{L W_{R_{i}}}{P f * L W_{C_{i}}} * 100
$$

16 where $\mathrm{RI}_{\mathrm{i}}$ is the roe index calculated per month per port (i), $\mathrm{LW}_{\mathrm{Ri}}$ is the landed weight of

17 roe per month per port (i) and Pf is the proportion of female fish in the landed catch.

$18 \mathrm{LW}_{\mathrm{Ci}}$ refers to the monthly total live weight of cod landed each month to each port (i)

19 from IVa and IVb. Eq. 2 is an adaptation of that used in Pederson (1984). As in Pederson

20 (1984), the proportion of females present in the catch (Pf) was assumed to be 0.5. Eq. 2

21 was used to calculate RI for landings to each port, each month (i) from IVa and IVb. RI

22 could not be estimated for VIIa, as the landings of cod from VIIa were unavailable. 
1 Experimental evidence has previously shown the average GSI of mature female cod to be

2 around 20-30 at peak spawning (Hansen et al., 2001, Kjesbu et al., 2010), so an RI much

3 higher than these values is likely to be spurious. However, when using the landings

4 datasets it was not possible to disentangle potential sources of error resulting in spurious

5 RI estimates. For example, high values of RI could be produced due to a high degree of

6 contamination of the data by a species of roe other than cod, by unreported discarding of

7 whole cod, or through errors in the recording of landed weight of cod or roe, which would

8 bias subsequent analysis. Alternatively, the sex ratio assumption could be consistently

9 underestimating the proportion of females in the catch, which could produce high values

10 of RI without biasing the estimation of PRM. An RI value of 50 was chosen as a cut-off

11 point to omit the most unlikely estimates. In IVa, 14 outlying data points were removed

12 with RI values ranging from 74-561. In IVb, 12 outlying data points were removed with

13 RI values which ranged from 51-759. The remaining RI values higher than 30 made up a

14 very small proportion of the total remaining data for each region (IVa: $0.58 \%, \mathrm{IVb}$ :

$15 \quad 3.6 \%)$.

16 The use of RI as a weighting factor for calculating PRM assumes that peaks in RI are

17 related consistently to phenology of spawning. Cycles in the analogous GSI can be used

18 to indicate spawning cycles in fish populations over time (Jons and Miranda, 1997). RI

19 increases as adult cod direct energy allocation to gonad growth prior to spawning, peaks

20 around the commencement of spawning, and decreases after the initiation of spawning as

21 roes become unsuitable for human consumption (Pederson, 1984). The RI was therefore

22 explored graphically to check that it followed a roughly bell-shaped distribution each

23 year. 
1 Statistical analysis

$2 \quad$ Trends in peak roe month

3 Before temporal trends in the timing of PRM were analysed, the presence of serial

4 correlation in PRM values was investigated tested for using the autocorrelation function

5 (ACF) in R (R Core Team, 2015). The value of the ACF at different time lags provides an

6 indication of whether there is any autocorrelation in the data. No significant

7 autocorrelation $(\mathrm{p}>0.05)$ was detected in the time series of PRM calculated for each

8 region, using either $\mathrm{RI}$ or $\mathrm{LW}_{\mathrm{R}}$ as a weighting factor. Temporal trends in PRM for each

9 region were then investigated through linear regression. The slope fitted to the regression

10 of PRM against year provided estimates of rate of change in months per year. These rates

11 were used to calculate rate of change in spawning time in weeks per decade, so that

12 results could be compared with results from similar research on sole (Fincham et al.,

13 2013).

14 Regional differences in PRM, and in temporal trends in PRM, were analysed through

15 analysis of covariance (ANCOVA), with year, region and the interaction between year

16 and region included as explanatory variables. Analyses were carried out with PRM

17 weighted by RI for IVa and IVb, and by $\mathrm{LW}_{\mathrm{R}}$ for IVa, IVb and VIIa.

18 To test whether PRM weighted by RI and PRM weighted by $\mathrm{LW}_{\mathrm{R}}$ provided similar

19 estimates of temporal trends in spawning time, an ANCOVA was fitted to compare the

20 difference in PRM, and trends in PRM over the years, when calculated using the two

21 different weighting factors. The model was fitted with PRM as response variable, year,

22 weighting factor, and the interaction between year and weighting factor as explanatory

23 variables. 
2 Prior to analysis of temporal trends in temperature, the datasets of seasonal SST averages

3 were tested for presence of autocorrelation using the ACF function in R. As no significant

4 autocorrelation was detected ( $\mathrm{p}>0.05)$, analysis of temporal trends was conducted using

5 simple linear regression. Linear regressions were fitted for each region with average

6 seasonal SST as the response variable and year as the explanatory variable. This analysis

7 was conducted separately for autumn and winter. The slopes estimated from the linear

8 regressions were used to calculate the rate of change in temperature over time. To test

9 whether directional trends in SST over time differed significantly between regions, an

10 ANCOVA was carried out with seasonal SST as the response variable and year, region

11 and the interaction between year and region as fixed effects. This analysis was repeated

12 for each season.

\section{Relationship between spawning phenology and temperature}

14 To test for correlations between PRM and autumn and winter SST, regressions were

15 carried out with PRM as the response variable and autumn or winter SST as the

16 explanatory variables. As the seasonal SST averages encompass a range of temperature

17 estimates across the area of each fishing area over three months there is considerable error

18 associated with each average which simple linear regression would not account for. The

19 exact location and thermal experience of sampled cod is unknowable, so including the

20 error associated with estimates of seasonal SST averages in the model accounts for some

21 of the uncertainty associated with this variable. Deming regression, a form of type II

22 regression analysis, was therefore carried out. In a Deming regression model, the

23 regression line is fitted by minimising the sum of squares for the perpendicular distance

24 between the data points and the regression line, therefore producing a single line 
1 regardless of which of the two variables is used as the response variable (Cornbleet and

2 Gochman, 1979). The advantage of Deming regression analysis is that error in the

3 explanatory as well as the response variable can be included in the model (Cornbleet and

4 Gochman, 1979). The estimates of standard error calculated for each estimate of average

5 seasonal SST and PRM were incorporated into the model, using the "deming" package in

6 R. The significance of the slope estimate was assessed through inspection of the $95 \%$

7 confidence intervals (Nakagawa and Cuthill, 2007). These analyses were repeated for

8 each region.

$9 \quad$ Trends in spawner length

10 Trends in average body length of female spawners were analysed through linear

11 regression, with fish length as the response variable and year as explanatory variable.

12 This analysis was repeated for IVa and IVb.

13 All statistical analyses were carried out using R v3.2.5 (R Core Team, 2015).

\section{Results}

15 Trends in peak roe month

16 There was a negative relationship between PRM and year in all three regions when using

17 either $\mathrm{LW}_{\mathrm{R}}\left(\mathrm{IVa}: \mathrm{F}_{1,28}=45.96, \mathrm{p}<0.001 ; \mathrm{IVb}: \mathrm{F}_{1,27}=60.09\right.$, $\mathrm{p}<0.001$; VIIa: $\mathrm{F}_{1,31}=18.92$,

$18 \mathrm{p}<0.001)$ or RI (IVa: $\left.\mathrm{F}_{1,28}=11.56, \mathrm{p}=0.002 ; \mathrm{IVb}: \mathrm{F}_{1,27}=17.65, \mathrm{p}<0.001\right)$ as the weighting

19 factor (Figure 3).

20 Neither estimates of average PRM (IVa: $\mathrm{F}_{1,56}=1.243$, $\mathrm{p}=0.27$; IVb: $\mathrm{F}_{1,54}=0.001$, $\mathrm{p}=0.97$ ),

21 nor trends in PRM over the years (IVa: $\mathrm{F}_{1,54}=0.589, \mathrm{p}=0.45, \mathrm{IVb}: \mathrm{F}_{1,54}=1.52, \mathrm{p}=0.22$ )

22 differed significantly when weighted by either weighting factor, suggesting these 
1 weighting factors are interchangeable for calculating PRM using this dataset. However,

2 the rate of change of PRM calculated for both IVa and IVb was slightly higher when

3 weighted by $\mathrm{LW}_{\mathrm{R}}$ than when weighted by RI (Table 1 ).

4 ANCOVA revealed regional differences in the average PRM when weighted by $L_{R}$

$5 \quad\left(\mathrm{~F}_{2,86}=150.44, \mathrm{p}<0.001\right)$ or $\mathrm{RI}\left(\mathrm{F}_{1,55}=9.61, \mathrm{p}=0.003\right)$, with average PRM of cod earliest in

$6 \quad$ IVb and latest in VIIa (Table 1). The trends in PRM over time also varied between

7 regions when weighted by $\mathrm{LW}_{\mathrm{R}}\left(\mathrm{F}_{2,86}=11.77\right.$, $\left.\mathrm{p}<0.001\right)$ or $\mathrm{RI}\left(\mathrm{F}_{1,55}=3.98, \mathrm{p}=0.05\right)$, with

8 shifts in PRM fastest in IVb when weighted by either factor (Table 1).

9 Roe composition

10 The results from the questionnaires supported the assumption that the majority of roes

11 landed by Scottish fishermen were composed of cod. 94\% of participants reported landing

12 cod roe and $54 \%$ of the participants reported that more than $75 \%$ of the roe they landed

13 was cod. Participants reported landing cod, haddock, hake, whiting, saithe and ling roe.

14 After cod, haddock was the most commonly landed species, as $75 \%$ of participants

15 reported landing haddock roe. $21 \%$ of participants reported landing more haddock roe

16 than cod roe. This suggests that haddock is the species most likely to contaminate the roe

17 landings dataset. Of the respondents that reported landing more haddock than cod roe,

$1829 \%$ reported that they rarely landed any roe. This leaves only $12 \%$ of participants who

19 claimed to land a considerable amount of haddock roe. Anecdotal evidence from

20 discussions with fishermen suggested that some fishermen would not land haddock roe as

21 it is smaller in size compared to cod roe (owing to smaller individual body size of

22 individual haddock caught) and more difficult to handle than cod roe. Furthermore, in

23 Scottish fish markets demand is highest for cod roe, creating an incentive for landing 
1 predominantly cod gonads (D. Anderson, Aberdeen Fish Producers Organisation,

2 personal communication, January 2017).

3 Temperature trends

4 There was a significant, positive relationship between average autumn SST and year in all

5 three regions (Figure 4). Average autumn SST increased at a rate of $0.35^{\circ} \mathrm{C}$ per decade in

6 IVa $\left(\mathrm{F}_{1,29}=21.91 . \mathrm{p}<0.001\right), 0.48^{\circ} \mathrm{C}$ per decade in IVb $\left(\mathrm{F}_{1,29}=20.86, \mathrm{p}<0.001\right)$ and $0.36^{\circ} \mathrm{C}$

7 per decade in VIIa $\left(\mathrm{F}_{1,31}=26.8, \mathrm{p}<0.001\right)$. ANCOVA revealed a significant effect of year

$8\left(\mathrm{~F}_{1,88}=55.10, \mathrm{p}<0.001\right)$ and region $\left(\mathrm{F}_{2,88}=246.67, \mathrm{p}<0.001\right)$ on the average autumn SST.

9 Across the study period, average SST was $11.28^{\circ} \mathrm{C}$ in IVa, $12.86^{\circ} \mathrm{C}$ in IVb and $13.64^{\circ} \mathrm{C}$

10 in VIIa. There was no interaction between region and year $\left(\mathrm{F}_{2,88}=0.68, \mathrm{p}=0.51\right)$ in relation

11 to autumn SST, suggesting that the rates of autumn SST warming did not differ

12 significantly between regions.

13 There was no relationship between winter SST and year in IVa $\left(\mathrm{F}_{1,30}=2.094, \mathrm{p}=0.16\right)$ or

14 VIIa $\left(\mathrm{F}_{1,32}=2.75, \mathrm{p}=0.11\right)$ (Figure 4). There was a positive relationship between winter

$15 \mathrm{SST}$ and year in IVb, with winter SST increasing at a rate of $0.24^{\circ} \mathrm{C}$ per decade (Figure

16 4). Similarly to autumn SST, ANCOVA revealed a significant effect of year $\left(F_{1,95}=6.062\right.$,

$17 \mathrm{p}=0.016)$ and region $\left(\mathrm{F}_{2,95}=163.871, \mathrm{p}<0.001\right)$ on winter SST. Across the study period,

18 average winter SST was $7.94^{\circ} \mathrm{C}$ in IVa, $7.44^{\circ} \mathrm{C}$ in IVb and $9.42^{\circ} \mathrm{C}$ in VIIa. There was no

19 interaction between region and year in relation to winter $\operatorname{SST}\left(\mathrm{F}_{2,95}=1,134, \mathrm{p}=0.33\right)$, again

20 suggesting no significant difference between the long-term temperature trends in each

21 region.

22 Relationship between peak roe month and temperature 
1 Owing to the lack of a significant difference between PRM weighted by $L W_{R}$ and PRM

2 weighted by RI, analysis was conducted using PRM weighted by $\mathrm{LW}_{\mathrm{R}}$ to represent trends

3 in spawning phenology. This allowed results to be compared across all three regions.

4 PRM correlated negatively with autumn SST in all regions (Figure 5, Table 2). No

5 relationships between PRM and average winter SST were revealed for any region (Figure

6 5, Table 2). For regions and seasons where a significant relationship between PRM and

7 average seasonal SST was observed, the slope estimates from regression analyses were

8 used to calculate predicted shifts in spawning phenology in response to increases in SST

9 (Table 2). The rate of change in spawning time in relation to autumn temperature rise

10 ranged from 1.16 weeks per $1^{\circ} \mathrm{C}$ change in autumn SST in IVa, to 3.92 weeks per $1^{\circ} \mathrm{C}$

11 rise in autumn SST in VIIa.

12 Trends in spawner length

13 There was a negative trend in length of female spawner over time in fishing area IVa,

14 with average length decreasing at a rate of $20 \mathrm{~mm}$ per decade $\left(\mathrm{F}_{1,2252}=17.69, \mathrm{p}<0.001\right)$,

15 and in fishing area IVb, with average length decreasing at a rate of $79 \mathrm{~mm}$ per decade $\left(\mathrm{F}_{1}\right.$,

$16 \quad 2472=175.2, \mathrm{p}<0.001)$.

\section{Discussion}

18 The results suggest that over three decades cod spawning has been occurring

19 progressively earlier in two adjacent regions of the North Sea and in the Irish Sea. During

20 approximately the same period a shift to earlier spawning was observed for sole in both

21 the North and Irish Sea (Fincham et al., 2013). The study on sole estimated the long-term

22 trend towards earlier spawning at 1.5 weeks per decade (Fincham et al., 2013). In this

23 study, cod were estimated to have shifted their spawning time at a rate of roughly 0.9 
1 weeks per decade in the Irish Sea, between 1.8 and 2.4 weeks per decade in the central

2 North Sea, and between 0.8 and 1 week per decade in the northern North Sea. The

3 average rate of change in spawning time of sole therefore falls within the estimated rates

4 of change for cod. Differences between the two species likely result from the different

5 environmental conditions they experience given that sole is a shallow-water, coastal

6 species (Fincham et al., 2013), whereas cod is a deeper-water, demersal species. The rate

7 of change presented for sole is furthermore an average across several spawning stocks,

8 and therefore may include variation in rates between different local populations. Overall,

9 the shift towards earlier spawning time observed in these two species occupying a

10 warming regional sea can be interpreted as a common, cross-species response to climate

11 change.

12 Increasing autumn sea surface temperatures (SST) were observed for all regions in this

13 study between 1985 and 2015. This is consistent with previous research which has

14 demonstrated rapid increases in SST in the North Sea in the last few decades (MacKenzie

15 and Schiedek, 2007). In the present study, significant decadal trends were not found in

16 winter SST in all regions. Previous research has demonstrated that of all the seasons,

17 summer temperatures in the North Sea have increased most rapidly and consistently

18 (MacKenzie and Schiedek, 2007). The lack of a clear temporal trend in winter

19 temperatures in all regions might be attributed to the increase in extreme winter weather

20 events which have occurred due to rapid Arctic warming (Cohen et al., 2014). The

21 occurrence of intermittent colder winters, illustrated in Figure 4, prevents a clear warming

22 trend in winter SST from being observed over the 30-year period of this study.

23 The trend towards earlier spawning time in all three regions, which was negatively

24 correlated with a warming trend in autumn SST, supports the hypothesis that warming 
1 temperatures in the North Sea and Irish Sea are associated with a shift towards earlier

2 spawning of cod. The negative relationship between seasonal SST and PRM is consistent

3 with previous experiments which have shown that cod held at warmer temperatures

4 spawn earlier (Kjesbu et al., 2010). Therefore, the most parsimonious explanation of the

5 observed correlation between spawning time and temperature is that it reflects the causal,

6 relationship between temperature and oocyte development rate and subsequently

7 spawning date (Kjesbu et al., 2010). Stronger relationships were found between autumn

8 SST and PRM than between winter SST and PRM. Model predictions have suggested that

9 changes in temperature will have the greatest effect on spawning time the sooner after

10 vitellogenesis these changes occur. These results therefore agree with these predictions,

11 as vitellogenesis occurs around the autumnal equinox (Kjesbu, 1994).

12 Alternative mechanisms which could produce the temporal trends in PRM as calculated

13 from the roe landings dataset must be considered when interpreting the results. The

14 opportunistic roe landings dataset was collated from records from the fishing industry,

15 therefore variation in fishing effort could bias the data. For example, the management

16 measures which have been implemented in the North Sea and Irish Sea throughout the

17 time period of this study to aid the recovery of cod stocks may have affected the

18 distribution of fishing effort both spatially and temporally. Measures such as real-time

19 closures in Scottish waters since 2008 (ICES, 2015c), closures of spawning areas in the

20 North Sea in 2001 (Anon, 2001), closure of spawning areas in IVb in 2010 (Kraak et al.,

21 2013) and the continuous closure of spawning grounds in the Irish Sea since 2000 (ICES,

22 2005) may each have acted to direct fishing pressure away from spawning cod in the

23 study areas, potentially affecting roe landings. The potential bias associated with temporal

24 variation in fishing effort was addressed through the calculation of a RI. The RI

25 represents roe landed as a proportion of total cod landed, therefore adjusting for fishing 
1 effort. Estimates of PRM and trends in PRM calculated using RI or $\mathrm{LW}_{\mathrm{R}}$ did not differ

2 significantly, suggesting variation in fishing effort did not confound analysis. However,

3 the estimated rates of change in PRM were lower when weighted by RI than by $\mathrm{LW}_{\mathrm{R}}$. It is

4 possible that this is due to an overestimation of the rate of change in PRM when weighted

5 by $\mathrm{LW}_{\mathrm{R}}$, which would suggest that there was some non-biological factor influencing the

6 timing of roe landings. However, it is not obvious how the management measures

7 mentioned previously could produce a gradual but systematic shift in fishing effort to

8 earlier in the year throughout the northern and central North Sea.

9 Timing of peaks in roe landings could also be affected by market demand for roe. When

10 estimating average spawning times from roe landings, Pederson (1984) reported that

11 during years when there was a lack of demand for roe an earlier average spawning time

12 was calculated, as only the highest quality roe was retained and partially spent roe later in

13 the season was discarded. As there is a negative trend in reported roe landings from all

14 regions in this study, it could be hypothesised that this is due to a decreasing trend in

15 demand for roe. However, decreasing roe landings may simply be driven by reductions in

16 catches of cod in response to decreasing quotas (ICES, 2015a), rather than by a decline in

17 demand for roe.

18 The limited spatial resolution of the roe landings dataset prevented the delineation of

19 location of spawning cod more precisely than to fishing area. Each of the fishing areas for

20 which data was available likely encompass more than one cod spawning ground. Several

21 spawning aggregations of cod can be found in IVa, including concentrations west of

22 Orkney, around Shetland and within the Moray Firth (Wright et al., 2006). Anecdotal

23 evidence from surveyed fishermen suggested that cod spawning time differs between

24 spawning areas within the North Sea. Variation in timing of spawning within the central 
1 North Sea, related to distance from the coast, has been reported (Brander, 1994). Cod

2 spawning in the western Irish Sea appears to occur earlier than in the eastern Irish Sea

3 (Brander, 1994). There is a possibility that spawning cod respond to rising temperatures

4 through spatial shifts in spawning habitats, as has been recorded for Northeast Arctic cod

5 (Sundby and Nakken, 2008). However, previous studies using data storage tags to track

6 the movement of spawning cod in the North Sea have demonstrated that individuals

7 appear to show site fidelity to spawning sites (Neat et al., 2014). Without spatially

8 resolved data it is not possible to assess whether a shift in fishing effort to areas where

9 cod spawn earlier has occurred during this study period. However, this shift would have

10 to have occurred in all three regions studied here to result in the consistent, earlier trends

11 in PRM recorded.

12 It is well known that fishing can truncate the age and size structure of exploited fish

13 stocks (Brander, 2007). Warming sea temperatures can also result in cod maturing at

14 smaller sizes and younger ages (Drinkwater, 2005). Consistent with these observations,

15 the average length of spawners in the North Sea has decreased over the study period.

16 Given that larger cod in the North Sea begin spawning earlier than smaller individuals

17 (Kjesbu et al., 2010) the observed shift towards earlier spawning cannot be attributed to

18 shift in size structure of the stocks. The trend towards reduced size of spawners would be

19 expected to result in an opposite trend in spawning phenology than was observed. This

20 suggests that spawner length cannot be the only factor influencing the spawning

21 phenology of cod in the North Sea. If the trends in spawning time recorded here were

22 indeed driven by rising temperatures, the magnitude of the rate of change may actually

23 have been inhibited by concurrent demographic changes. 
1 Another factor which has been proposed as influencing spawning time of cod is dietary

2 lipid composition. Specifically, a delay in spawning time of eastern Baltic cod has been

3 linked to a reduction in the availability in cod prey of arachidonic acid (ARA), a lipid

4 associated with ovary development. This change in dietary lipid composition was

5 hypothesised to result from changes in the plankton composition of the Baltic Sea

6 (Røjbek et al., 2012). The phytoplankton and zooplankton communities in the North and

7 Irish Seas have undergone dramatic changes in phenology and biogeography in recent

8 decades (Alheit et al., 2005, Edwards and Richardson, 2004, Beaugrand et al., 2002). In

92003 North Sea cod ovaries were found to contain high levels of ARA (Tomkiewicz et

10 al., 2010). As cod around the UK are generalist feeders, with a diet dependent on prey

11 abundance and which can exhibit size-dependent temporal and spatial prey switching

12 behaviour (Trenkel et al., 2005, Pinnegar et al., 2003, Floeter and Temming, 2003), it

13 would be a complex task to assess whether changes in the plankton communities have

14 resulted in changes in the lipid and fatty acid composition of cod that in turn impacted

15 spawning time.

16 Of the various factors discussed above which could result in the trend towards earlier

17 PRM, rising temperature is currently the only variable for which there is consistent

18 evidence throughout the three regions. Furthermore, the trend is consistent with the

19 putative causal relationship between temperature, oocyte development rate and spawning

20 time (Kjesbu et al. 2010). The finding that advancing spawning phenology appears to be

21 correlated to warming autumn sea temperatures in three different regions has implications

22 for understanding the impacts of current and future climate change on cod populations.

23 The rates of change calculated here suggest that an increase in SST of $1^{\circ} \mathrm{C}$ may result in a

24 shift in cod spawning time of up to 3.92 weeks. Sea temperatures experienced by cod in

25 the North and Irish Seas are expected to continue to increase throughout the $21^{\text {st }}$ century, 
1 potentially warming by $2^{\circ} \mathrm{C}$ by 2100 (Drinkwater, 2005). In addition to temperature,

2 spawning phenology of cod is believed to be influenced by a combination of abiotic and

3 biotic factors, namely the age and size of mature fish (Morgan et al., 2013) and

4 photoperiodic cues (Kjesbu et al., 2010). Age and size at maturity may be influenced by

5 rising temperatures (Drinkwater, 2005) whereas photoperiodic cues could remain fixed.

6 The responses of spawning phenology to future climate change in this species, known to

7 be behaviourally flexible and with a wide thermal tolerance (Righton et al., 2010) are

8 therefore difficult to predict. However, the trend towards earlier spawning concurrent

9 with rising temperatures suggest that consideration of reproductive phenology is essential

10 when assessing the population-level response of cod to climate change.

11 Consequences of climate change-induced shifts in spawning phenology of cod include the

12 potential for a mismatch in timing with vital prey. Cod larvae rely particularly on

13 copepods as a major food source (Beaugrand et al., 2003), hence the timing of peaks in

14 larval abundance must overlap with peaks in copepod abundance to ensure survival of

15 larvae. Research on the impact of climate change on plankton phenology in the North Sea

16 has demonstrated that the timing of spring peaks in copepod abundance has no

17 relationship with SST (Edwards and Richardson, 2004). Between 1958 and 2002 the

18 average timing of the spring bloom did not change, likely because diatom phenology is

19 controlled by photoperiod rather than temperature (Edwards and Richardson, 2004). It has

20 already been demonstrated that climate change-induced changes in the composition and

21 succession within the plankton ecosystem in the North Sea has impacted cod recruitment

22 (Beaugrand et al., 2003). As spawning time is necessarily linked to timing of peaks in

23 larvae, the evidence presented in this study demonstrates how a temporal mismatch

24 between the arrival of cod larvae in the plankton and the spring plankton blooms could

25 occur and potentially further impact recruitment. It may be possible that such a 
1 mechanism has already been impacting cod recruitment, contributing to the slow recovery

2 of North Sea cod (ICES, 2015c) and the lack of recovery observed for Irish Sea cod

3 stocks (Kelly et al., 2006).

\section{Conclusion}

5 To date, no change in the growth rate of cod in the North Sea has occurred (Baudron et

6 al., 2014), and the evidence suggesting that there have been shifts in spatial distribution of

7 North Sea cod is equivocal (Righton et al., 2010). Therefore, climate change-induced

8 shifts in the reproductive phenology of cod may currently provide the strongest evidence

9 that rising temperatures have had a detectable impact on the life history of cod in the

10 North Sea. Owing to the coarse temporal and spatial resolution and opportunistic nature

11 of the datasets used in this study, the rates of change in spawning phenology calculated

12 here should be considered as preliminary estimates of overall trends. Further work to

13 validate these preliminary findings could involve tagging studies to quantify the

14 temperatures experienced by cod undergoing vitellogenesis and so validate SST as a

15 representative indicator of thermal experiences of cod. In addition, egg surveys could be

16 used to confirm that estimates of spawning time calculated through cumulative egg curves

17 correlate with those calculated through roe landings from the study regions (e.g.

18 Pederson, 1984). However, the agreement in observed trends in temperature and

19 spawning time across three different regions, which is contrary to the concurrent change

20 in size composition towards smaller spawners, provides consistent support for attributing

21 the change in phenology to warming temperatures. As a shift in spawning time has now

22 been suggested for two species in the North and Irish Sea, with divergent life-strategies

23 and exploitation histories, shifts in reproductive phenology may represent a synchronous

24 response to climate change across marine fish species in these regions. 
1

\section{Acknowledgements}

8 Thanks to Dr Mike Armstrong at Cefas for providing landings data from the Irish Sea and

\section{References}

Alheit, J., Möllmann, C., Dutz, J., Kornilovs, G., Loewe, P., Mohrholz, V., Wasmundm N., 2005. Synchronous ecological regime shifts in the central Baltic and North Sea in the late 1980s. ICES Journal of Marine Science, 62:1205-1215.

17

Anon, 2001. Commission Regulation (EC) No. 259/2001 of 7 February 2001 establishing measures for the recovery of the stock of cod in the North Sea (ICES subarea IV) and associated conditions for the control of activities of fishing Vessels. Official Journal of the European Communities (2001) L39/7

Armstrong, M.J., Connolly, P., Nash, R.D.M., Pawson, M., Alesworth, E., Coulahan, P.J., Dicky-Colas, M., Milligan, S.P., O’Neill, M., Witthames, P.R., Wolner, L., 2001. An application of the annual egg production method to estimate the spawning biomass of cod (Gadus morhua L.), plaice (Pleuronectes platessa L.) and sole (Solea solea L.) in the Irish Sea. ICES J. Mar Sci. 58, 183-203. 
Armstrong, M.J., Gerriston, H.D., Allen, M., McCurdy, W.J., Peel, J.A.D., 2004. Variability in maturity and growth in a heavily exploited stock: cod (Gadus morhua L.) in the Irish Sea. ICES Journal of Marine Science, 61: 98-112.

Baudron, A.R., Needle, C.L., Rijnsdorop, A.D., Marshall, C.T., 2014. Warming temperatures and smaller body sizes: synchronous changes in growth of North Sea fishes. Global Change Biology, 20: 1023-1031.

Belkin, I.M., 2009. Rapid warming of large marine ecosystems. Progress in Oceanography, 81: 207-213.

Beaugrand, G., Reid, P.C., Ilbañez, F., Lindley, J.A., Edwards, M., 2002. Reorganization of North Atlantic marine copepod biodiversity and climate. Science, 296: 16921694.

Beaugrand, G., Brander, K.M., Lindley, J.A., Souissu, S., Reid, P.C., 2003. Plankton effect on cod recruitment in the North Sea. Nature, 426: 661-664.

Brander, K.M., 1994. The location and timing of cod spawning around the British Isles. ICES Journal of Marine Research, 51: 71-89.

Brander, K.M., 1995. The effect of temperature on growth of Atlantic cod (Gadus morhua L.). ICES Journal of Marine Science, 52:1-10.

Brander, K.M., 2007. Global fish production and climate change. PNAS, 104: 1970919714.

Carscadden, J., Nakashima, B.S., Frank, K.T., 1996. Effects of fish length and temperature on the timing of peak spawning in capelin (Mallotus villosus). Canadian Journal of Fisheries and Aquatic Science, 54: 781-787.

Clark, R.A., Fox, C.J., Viner, D., Livermore, M., 2003. North Sea cod and climate change - modelling the effects of temperature on population dynamics. Global Change Biology, 9: 1669-1680. 
1

2 3

5

6

7

8

9

10

11

12

13

14

15

16

17

18

19

20

21

22

23

24

25

26

27

28

29

30

31

32

33

Cohen, J., Screen, J.A., Furtado, J.C., Barlow, M., Whittleston, D., Coumou, D., Francis, J., Dethloff, K., Entekhabi, D., Overland, J., Jones, J., 2014. Recent Arctic amplification and extreme mid-latitude weather. Nature Geoscience, 7: 627-637.

Connor, D.W., Gilliland, P.M., Golding, N., Robinson, P., Todd, D., Verling, E., 2006. UKSeaMap: the mapping of seabed and water column features of UK seas. Joint Nature Conservation Committee, Peterborough.

Cornbleet, P.J., Gochman, N., 1979. Incorrect least-squares regression coefficients in method-comparison analysis. Clinical Chemistry, 25: 432-438.

Cushing, D.H., 1975. Marine Ecology and Fisheries. Cambridge University Press, Cambridge, UK.

Cushing, D.H., 1990. Plankton production and year-class strength in fish populations-an update of the match mismatch hypothesis. Advances in Marine Biology, 26: 249292.

Drinkwater, K.F., 2005. The response of Atlantic cod (Gadus morhua) to future climate change. ICES Journal of Marine Science, 62: 1327-1337.

Dufour, F., Arrizabalaga, H., Irigoien, X., Santiago, J., 2010. Climate impacts on albacore and bluefin tunas migrations phenology and spatial distribution. Progress in Oceanography, 86: 283-290.

Dulvy, N.K., Rogers, S.I., Jennings, S., Stelzenmüller, V., Dye, S.R., Skjodal, H.R., 2008. Climate change and deepening of the North Sea fish assemblage: a biotic indicator of warming seas. Journal of Applied Ecology, 45: 1029-1039.

Edwards, M., Richardson, A.J., 2004. Impact of climate change on marine pelagic phenology and trophic mismatch. Letters to Nature, 430: 881-884. 
Engelhard, G.H., Pinnegar, J.K., Kell, L.T., Rijnsdorp, A.D., 2011. Nine decades of North Sea sole and plaice distribution. ICES Journal of Marine Science, 68: 1090-1104.

Engelhard, G.H., Righton, D.A., Pinnegar, J.K., 2014. Climate change and fishing: a century of shifting distribution in North Sea cod. Global Change Biology, 20: 2473-2483.

Fincham, J., Rijnsdorp, A.D., Engelhard, G.H., 2013. Shifts in the timing of spawning in sole linked to warming sea temperatures. Journal of Sea Research, 75: 69-76.

Floeter, J., Temming, A., 2003. Explaining diet composition of North Sea cod (Gadus morhua): prey size preference vs. prey availability. Canadian Journal of Fisheries and Aquatic Sciences, 60:140-150.

Greve, W., Prinage S., Zidowitz, H., Nast, J., Reiners, F., 2005. On the phenology of North Sea icthyoplankton. ICES Journal of Marine Science, 62: 1216-1223.

Hansen, T., Karlsen, Ø., Taranger, G.L., Hemre, G., Holm, J.C., Kjesbu, O.S., 2001. Growth, gonadal development and spawning time of Atlantic cod (Gadus morhua) reared under different photoperiods. Aquaculture, 203: 51-67.

Hjort, J., 1914. Fluctuations in the great fisheries of Northern Europe viewed in the light of biological research. Rapports et Procès-Verbaux des Réunions du Conseil Permanent International Pour L'Exploration de la Mer, 20: 1-228.

Hughes, L., 2000. Biological consequences of global warming: is the signal already apparent? Trends in Ecology and Evolution, 15: 56-61.

Hutchings, J.A., Myers, R.A., 1994. Timing of cod reproduction: interannual variability and the influence of temperature. Marine Ecology Progress Series, 108: 21-31.

ICES, 2005. Spawning and life history information for North Atlantic cod stocks. ICES Cooperative Research Report, No. 274. 152 pp. 
1

ICES, 2014. Celtic Sea and west of Scotland cod in division VIIa (Irish Sea). ICES Advice 2014, Book 5:5.3.5

ICES, 2015a. ICES Advice on fishing opportunities, catch and effort Greater North Sea and Celtic Seas Ecoregions, ICES Advice 2015, Book 6: 6.3.4

ICES. 2015b. Manual for the International Bottom Trawl Surveys. Series of ICES Survey Protocols SISP 10 - IBTS IX. 86 pp.

ICES, 2015c. Report of the Working Group on the Assessment of Demersal Stocks in the North Sea and Skagerrak (WGNSSK), 28 April-7 May, ICES HQ, Copenhagen, Denmark. ICES CM 2015/ACOM:13. 1229 pp.

IPCC, 2013: Summary for Policymakers. In: Climate Change 2013: The Physical Science Basis. Contribution of Working Group I to the Fifth Assessment Report of the Intergovernmental Panel on Climate Change [Stocker, T.F., D. Qin, G.-K. Plattner, M. Tignor, S.K. Allen, J. Boschung, A. Nauels, Y. Xia, V. Bex and P.M. Midgley (eds.)]. Cambridge University Press, Cambridge, United Kingdom and New York, NY, USA.

Jansen, T., Gislason, H., 2011. Temperature affects the timing of spawning and migration of North Sea mackerel. Continental Shelf Research, 31: 64-72.

Jons, G.D., Miranda, L.E., 1997. Ovarian weight as an index of fecundity, maturity and spawning periodicity. Journal of Fish Biology, 50: 150-156.

Katsiadaki, I.G., Taylor, K.D.A., Smith, G., 1999. Assessment of quality of cod roes and relationship between quality and maturity stage. Journal of Science of Food and Aquaculture, 79: 1249-1259.

Kelly, C.J., Codling, E.A., Rogan, E., 2006. The Irish Sea cod recovery plan: some lessons learned. ICES Journal of Marine Science, 63: 600-610. 
Kjesbu, O.S., 1994. Time of start of spawning in Atlantic cod (Gadus morhua) females in relation to vitellogenic oocyte diameter, temperature, fish length and condition. Journal of Fish Biology, 45: 719-735.

Kjesbu, O.S., Righton, D., Krüger-Johnesn, M., Thorsen, A., Michalsen, K., Fonn, M., Whitthames, P.R., 2010. Thermal dynamics of ovarian maturation in Atlantic cod (Gadus morhua). Canadian Journal of Fisheries and Aquatic Sciences, 67: 605-625.

Kraak, S.B.M., Bailey, N., Cardinale, M., Darby, C., De Oliveira, J.A.A., Eero, M., Graham, N., Holmes, S., Jakobsen, T., Kempf, A., Kirkegaard, E., Powell, J., Scott, R.D., Simmonds, E.J., Ulrich, C., Vanhee, W., Vinther, M., 2013. Lessons for fisheries management from the EU cod recovery plan. Marine Policy, 37: 200-213.

MacKenzie, B.R., Schiedek, D., 2007. Daily ocean monitoring since the 1860 s shows record warming of northern European seas. Global Change Biology, 13: 13351347.

Morgan, M.J., Wright, P.J., Rideout, R.M., 2013. Effect of age and temperature of spawning time in two gadoid species. Fisheries Research, 138: 2-51.

Nakagawa, S., Cuthill, I.C., 2007. Effect size, confidence interval and statistical significance: a practical guide for biologists. Biological Reviews, 82: 591-605.

Neat, F., Righton, D., 2007. Warm water occupancy by North Sea cod. Proceedings of the Royal Society B., 274: 789-798.

Neat, F.C., Bendall, V., Berx, B., Wright, P.J., Ó Cuaig, M., Townhill, B., Schön, P., Lee, J., Righton, D., 2014. Movement of Atlantic cod around the British Isles; implications for finer scale stock management. Journal of Applied Ecology, 51: 1564-1574.

Perry, A.L., Low, P.J., Ellis, J.R., Reynolds, J.D., 2005. Climate change and distribution shifts in marine fishes. Science, 308: 1912-1915. 
1

2

3

4

5

6

7

8

9

10

11

12

13

14

15

16

17

18

19

20

21

22

23

24

25

26

27

28

29

30

31

32

33

34

35

Pederson, T., 1984. Variation of peak spawning of Arcto-Norwegian cod (Gadus morhua L.) during the time period 1929-1982 based on indices estimated from fishery statistics. In: The propagation of cod Gadus morhua L.: an international symposium, Arendal, 14-17 June 1983.

Pinnegar, J.K., Trenkel, V.M., Tidd, A.N., Dawson, W.A., Du buit, M.H., 2003. Does diet in Celtic Sea fishes reflect prey availability? Journal of Fish Biology, 63:197212.

Planque, B., Frédou, T., 1999. Temperature and the recruitment of Atlantic cod (Gadus morhua). Canadian Journal of Fisheries and Aquatic Sciences, 56: 2069-2077.

Platt, T., Fuentes-Yaco, C., Frank, K.T., 2003. Spring algal bloom and larval fish survival. Nature, 423: 398-399.

R Core Team, 2015. R: A language and environment for statistical computing. $\mathrm{R}$ Foundation for Statistical Computing, Vienna, Austria. URL http:/www.Rproject.org/.

Rayner, N.A., Parker, D.E., Horton, E.B., Folland, C.K., Alexander, L.V., Rowell, D.P., Kent, E.C., Kaplan, A., 2003. Global analyses of sea surface temperature, sea ice, and night marine air temperature since the late nineteenth century. Journal of Geophysical Research, 108: 4407, doi:10.1029/2002JD002670.

Righton, D.A., Anderson, K.H., Neat, F., Thorsteinsson, V., Steingrund, P., Svedäng, H., Michalsen, K., Hinrischen, H., Bendall, V., Neuenfeldt, S., Wright, P., Jonsson, P., Huse, G., Krooij, J., Mosegaard, H., Hüssy, K., Metcalfe, J., 2010. Thermal niche of Atlantic cod Gadus morhua: limits, tolerances and optima. Marine Ecology Progress Series, 420: 1-13.

Roberts, A.M.I., Tansey, C., Smithers, R.J., Phillimore, A.B., 2015. Predicting a change in the order of spring phenology in temperate forests. Global Change Biology, 21: 2603-2611. 

3

Rogers, S., Stocks, R., 2001. North Sea fish and fisheries. Strategic Environmental Assessment - SEA2, Technical Report 003 - Fish \& Fisheries. CEFAS, FRS.

Røjbek, M.C., Jacobsen, C., Tomkiewicz, J., Støttrup, J.G., 2012. Linking lipid dynamics with the reproductive cycle in Baltic cod Gadus morhua. Marine Ecology Progress Series, 471: 215-234.

Roy, D.B., Sparks, T.H., 2000. Phenology of British butterflies and climate change. Global Change Biology, 6: 407-416.

Sundby, S., Nakken, O., 2008. Spatial shifts in spawning habitats of Arcto-Norwegian cod related to multidecadal climate oscillations and climate change. ICES Journal of Marine Science, 65: 953-962.

Tomkiewicz, J., Støttrup, J.G., Jacobsen, C., Røjbek, M., Köster, F., 2010. Influence of lipids and fatty acid composition on Baltic cod (Gadus morhua L.) maturation and timing of spawning. Abstract from ICES Council Meeting 2009, Berlin, Germany.

Trenkel., V.M., Pinnegar, J.K., Dawson, W.A., de Buit, M.H., Tidd, A.N., 2005. Spatial and temporal structure of predator-prey relationships in the Celtic Sea fish community. Marine Ecology Progress Series, 299:257-268.

Wieland, K., Jarre-Teichmann, A., Horbowa K., 2000. Changes in the timing of spawning of Baltic cod: possible causes and implications for recruitment. ICES Journal of Marine Science, 57:452-464.

Wright, P.J., Galley, E., Gibb, I.M., Neat, F.C., 2006. Fidelity of adult cod to spawning grounds in Scottish waters. Fisheries Research, 77: 148-158. 
1 Tables

2 Table 1: Average peak roe month (PRM) and rate of change in PRM over the study

3 period, for each region and calculated using each weighting factor (landed weight of roe

$4 \quad\left(\mathrm{LW}_{\mathrm{R}}\right)$ and roe index $\left.(\mathrm{RI})\right)$. Presented is the slope and associated error estimated by the

5 regression models, interpreted as an estimate of change in months per year. The rate of

6 change in PRM in weeks per decade calculated from this slope is also presented.

\begin{tabular}{lllll}
\hline Region & $\begin{array}{l}\text { Weighting } \\
\text { factor }\end{array}$ & $\begin{array}{l}\text { Average } \\
\text { PRM }\end{array}$ & $\begin{array}{l}\text { Slope } \\
\pm \text { Standard error }\end{array}$ & $\begin{array}{l}\text { Rate of } \\
\text { Change in } \\
\text { PRM (weeks } \\
\text { per decade) }\end{array}$ \\
\hline IVa & $\mathrm{LW}_{\mathrm{R}}$ & 2.34 & $-0.024 \pm 0.0035$ & 1.03 \\
$\mathbf{I V a}$ & $\mathrm{RI}$ & 2.41 & $-0.019 \pm 0.0056$ & 0.81 \\
$\mathbf{I V b}$ & $\mathrm{LW}$ & 2.11 & $-0.057 \pm 0.0073$ & 2.44 \\
$\mathbf{I V b}$ & $\mathrm{RI}$ & 2.11 & $-0.041 \pm 0.0099$ & 1.76 \\
VIIa & $\mathrm{LW}$ & 3.21 & $-0.022 \pm 0.0051$ & 0.94 \\
\hline
\end{tabular}

7 
1 Table 2: The relationship between peak roe month (PRM) weighted by landed weight of

2 roe $\left(\mathrm{LW}_{\mathrm{R}}\right)$ and seasonal sea surface temperature (SST), analysed using Deming

3 regression. The slope estimate can be interpreted as rate of change in month per ${ }^{\circ} \mathrm{C}$

4 change in temperature. Statistically significant slope estimates (i.e. $95 \%$ confidence

5 intervals do not contain zero) are emboldened. For statistically significant relationships

6 the regression slope for the model has been used to estimate a rate of change in weeks per

$7{ }^{\circ} \mathrm{C}$.

\begin{tabular}{|c|c|c|c|c|c|}
\hline Season & Region & $\begin{array}{c}\text { Weighting } \\
\text { Factor }\end{array}$ & $\begin{array}{c}\text { Deming slope } \\
\text { estimate } \pm \\
\text { Standard error }\end{array}$ & $\begin{array}{c}95 \% \\
\text { confidence } \\
\text { interval for } \\
\text { Deming slope } \\
\text { estimate } \\
\text { (lower, } \\
\text { upper) }\end{array}$ & $\begin{array}{c}\text { Rate of } \\
\text { change }(\text { week } \\
\left.\text { per }{ }^{\circ} \mathrm{C}\right) \\
\text { estimated } \\
\text { from Deming } \\
\text { slope }\end{array}$ \\
\hline \multirow{3}{*}{ Autumn } & IVa & $\mathrm{LW}_{\mathrm{R}}$ & $\mathbf{- 0 . 2 9} \pm 0.059$ & $-0.41,-0.18$ & 1.16 \\
\hline & $\mathrm{IVb}$ & $\mathrm{LW}_{\mathrm{R}}$ & $\mathbf{- 0 . 4 1} \pm 0.14$ & $-0.67,-0.14$ & 1.64 \\
\hline & VIIa & $\mathrm{LW}_{\mathrm{R}}$ & $\mathbf{- 0 . 9 8} \pm 0.30$ & $-1.57,-0.38$ & 3.92 \\
\hline \multirow{3}{*}{ Winter } & IVa & $\mathrm{LW}_{\mathrm{R}}$ & $-0.041 \pm 0.11$ & $-0.26,0.18$ & \\
\hline & $\mathrm{IVb}$ & $\mathrm{LW}_{\mathrm{R}}$ & $-0.35 \pm 0.36$ & $-1.05,0.36$ & \\
\hline & VIIa & $\mathrm{LW}_{\mathrm{R}}$ & $-1.55 \pm 0.79$ & $-3.10,0.01$ & \\
\hline
\end{tabular}


Figure 1: The location of ICES fishing grounds IVa and IVb in the North Sea, and VIIa in the Irish Sea, from which records of landings of roe were available.

Figure 1

$616 \times 553 \mathrm{~mm}(96 \times 96$ DPI $)$ 
IVa
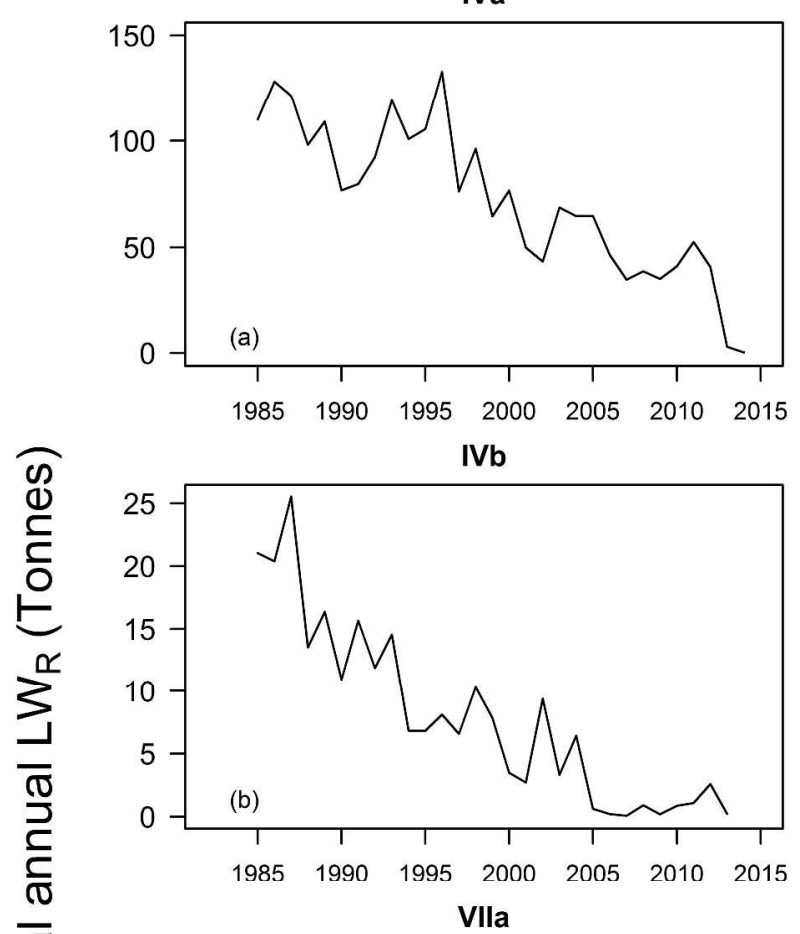

뮴

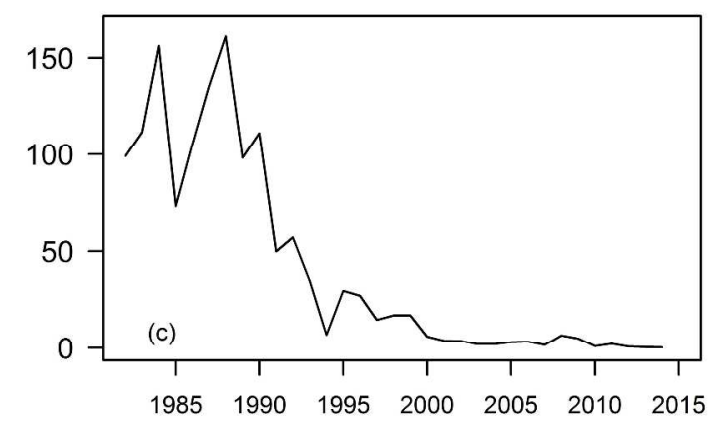

Year

Figure 2: The total annual landed weight of roe (LWR), landed during months January to April from regions IVa (a) and IVb (b) and during February to May from region VIIa (c). Figure 2

$177 \times 311 \mathrm{~mm}(600 \times 600 \mathrm{DPI})$ 
Weighted by $L W_{R}$
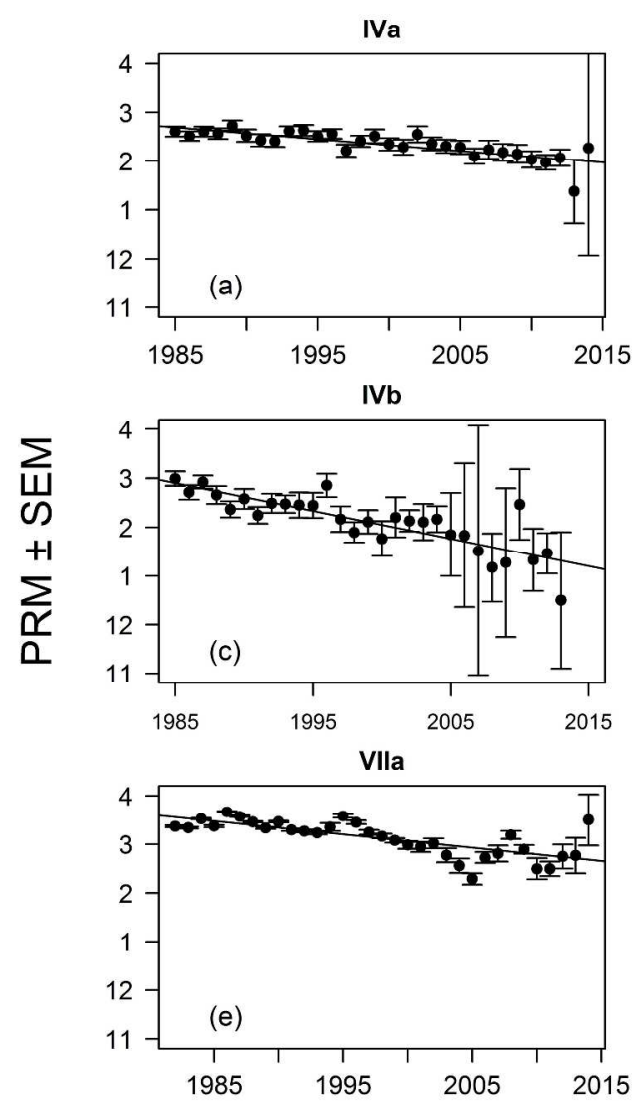

Weighted by RI
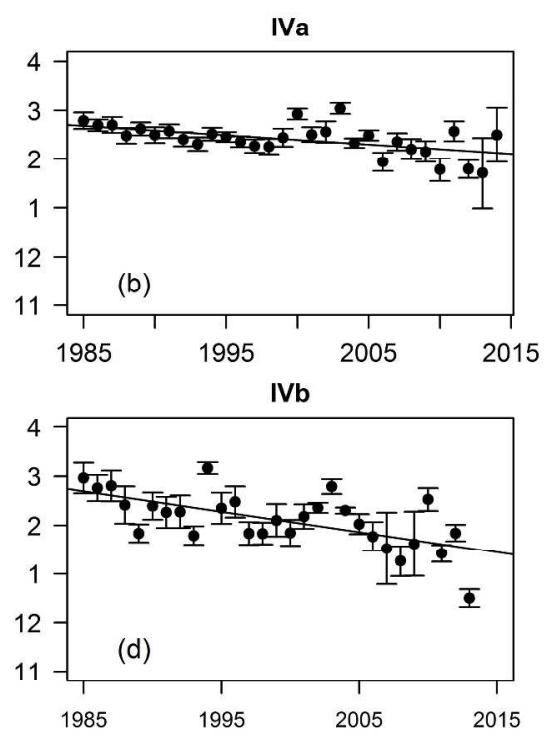

Year

Figure 3: The relationship between peak roe month (PRM) and year in regions IVa, IVb and VIIa, when weighted by either landed weight of roe (LWR) or roe index (RI). Regression lines are included to indicate a significant $(p<0.05)$ trend in PRM over time, based on linear regression analysis. Standard error bars are included to illustrate the standard error of the mean (SEM) associated with each estimate of PRM, but were not included in regression analyses.

\section{Figure 3}

$169 \times 169 \mathrm{~mm}(600 \times 600 \mathrm{DPI})$ 


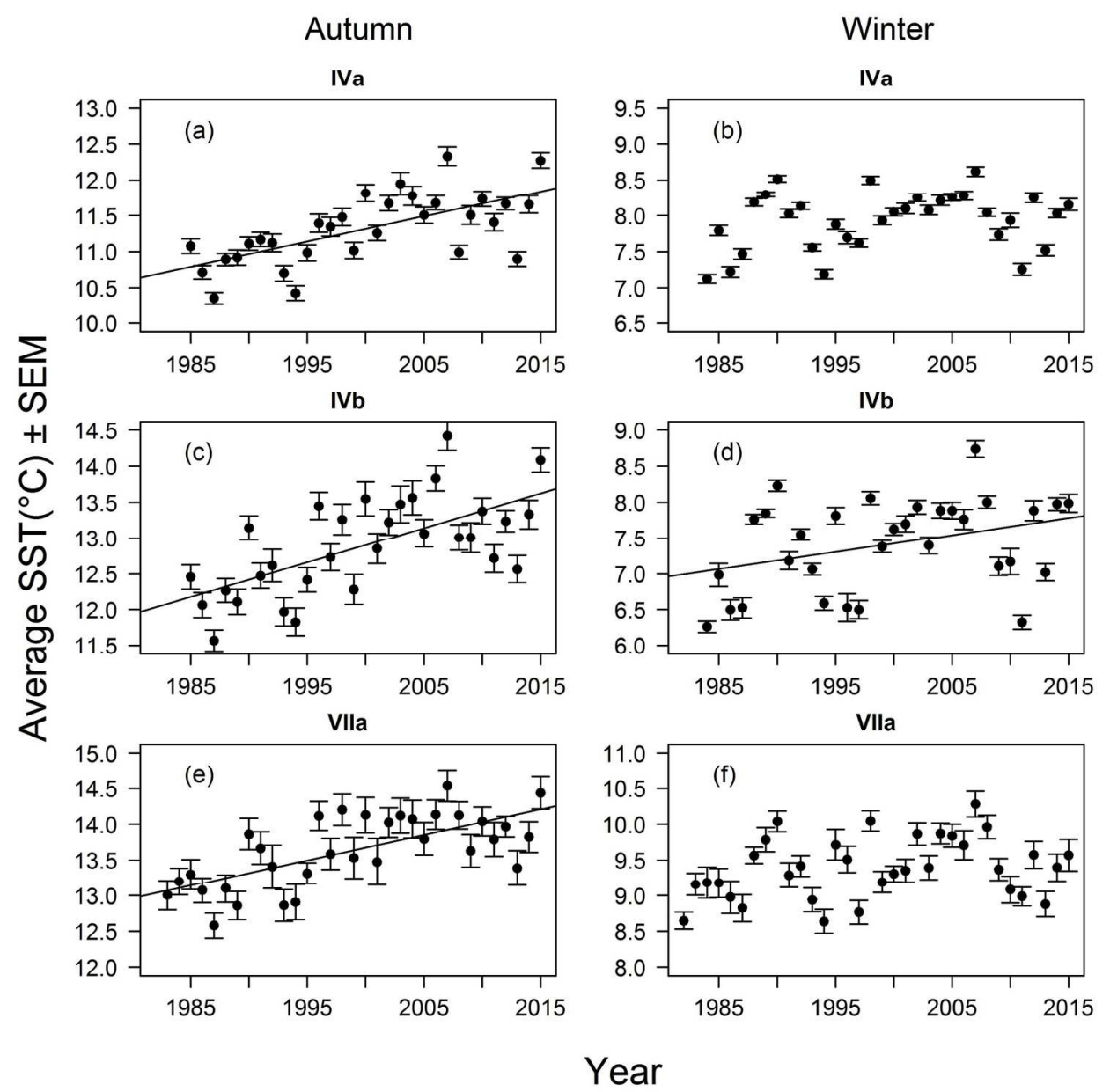

Figure 4: The trends in sea surface temperature (SST) over time, for autumn and winter averages in regions IVa, IVb and VIIa. Standard error bars are included to illustrate the standard error of the mean (SEM) for each of the calculated seasonal means, but were not included in regression analyses. Regression lines are included where there was a significant trend $(p<0.05)$ in the seasonal mean SST over time.

Figure 4

$169 \times 169 \mathrm{~mm}(300 \times 300$ DPI $)$ 

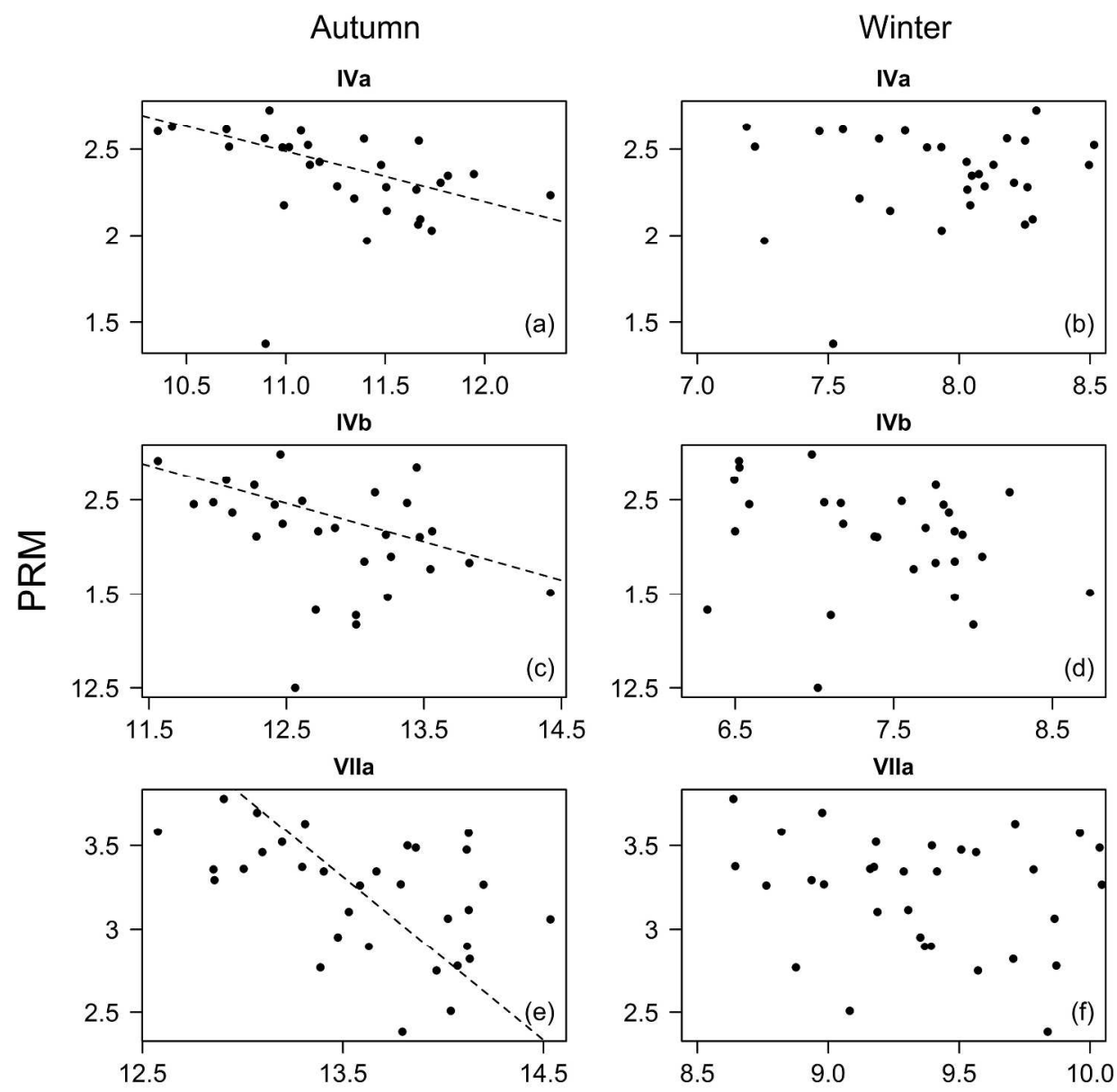

Average $\operatorname{SST}\left({ }^{\circ} \mathrm{C}\right)$

Figure 5: The relationship between landed weight of roe (LWR) weighted peak roe month (PRM) and average seasonal sea surface temperature (SST). Dashed lines indicate significant relationships as calculated through Deming regression ( $95 \%$ confidence intervals do not contain zero).

Figure 5 $129 \times 129 \mathrm{~mm}(600 \times 600 \mathrm{DPI})$ 